\title{
Construction of Plan Environmental Impact Assessment System in China
}

\author{
Z. Y. Shen", X. W. Ding and Z. F. Yang \\ State Key Joint Laboratory of Environmental Simulation and Pollution Control, School of Environment, \\ Beijing Normal University, Beijing 100875, China
}

\begin{abstract}
Strategic Environmental Assessment (SEA) is a frontier subject in the field of Environmental Impact Assessment (EIA), which means the environmental assessment process for strategic actions: policies, plans or programs (PPPs). At present, Plan Environmental Impact Assessment (PEIA), the plan level of SEA, is legally required in China and the government has published a recommended technical guideline for it. This paper introduces the progress of PEIA in China and summarizes three developing phases and introduces their characteristics. According to Environmental Impact Assessment Law of the People's Republic of China (EIALPRC), the article describes the current PEIA system in China, mainly focusing on assessor, assessment targets, assessment requirements, assessment contents, assessment methods and working procedure of PEIA etc. Finally, some recommendations are proposed by the authors in order to improve PEIA in China as follows: conforming to the principle of "intervening in early stage", achieving synchronous EIA of all plans; implementing classification management on PEIA according to the degree of environmental impacts of plans; and enhancing efficiency of alternative schemes in the process of planning.
\end{abstract}

Keywords: China, EIALPRC, PEIA, Plan, SEA, System

\section{Introduction}

Strategic Environmental Assessment (SEA) is "the formalized, systematic and comprehensive process of evaluating the environmental effects of a policy, plan or programme and its alternatives" (Therivel et al., 1992). In the past decades, a lot of researches have been done on assessment targets, methodology, working procedure of SEA, and the relationship between SEA and Environmental Impact Assessment (EIA) by the scholars from USA, Britain, Canada, China, etc., which has offered the concrete and feasible guides for implementation of SEA (Carson, 1992; Therivel and Roasrio, 1996; Noble, 2000; Bao et al., 2004). In practice, SEA mainly concentrates on the traffic planning proposals, sustainable development strategies of river basins, globalization influence of traffic policies, transformation of energy technology, and wastewater discharge standard, etc. (Gardiner, 1994; Kahen, 1997; Dodgn, 1997; Rosa and Natalia, 2000; Noble, 2003). Considering the necessity and importance of SEA, some countries have set up assessment systems of SEA, such as in Canada, Britain, USA, Holland, and New Zealand, etc. Similarly, China enacted EIALPRC (CNPCSC, 2002), in which PEIA (the plan level of SEA) is regulated legally.

PEIA is environmental assessment process for plan and its alternatives, and it is in the plan level of SEA construction system. Take account of connotation of PEIA, PEIA still belongs to SEA. Over ten years in the past, a large amount of theoretical researches on PEIA have been done in China, a

\footnotetext{
* Corresponding author: zyshen@tsinghua.org.cn
}

systemic assessment system has been formed, and some PEIA cases have been conducted on the plans with large-scale or serious environmental impacts. Assessment targets focus on plans which may cause significant environment impact, and different working procedures should be taken for various assessment targets ( $\mathrm{Ju}$ and $\mathrm{Zhu}, 2003$ ). The scope, duty, and legal responsibility of assessor are discussed mainly, and strengthening legal liability consciousness of assessor can enhance the efficiency of PEIA (Huang and Tang, 2003). Many methods are adopted into PEIA, such as predict models used in traditional EIA, methods used in planning and decision-making, and GIS etc. For example, input-output approach is used in industry structure adjustment (Ma et al., 2003) and air quality prediction is applied in comprehensive transportation planning (Huang et al., 2003). Working procedure of PEIA in China can be concluded as following: (1) Screening: determining the necessity of PEIA; (2) Identifying goals of plan and environmental protection; (3) Scoping: analyzing the state of the environment and identifying alternatives; (4) Predicting and appraising environment impact; (5) Consulting experts and public participation; (6) Decision making; and (7) Monitoring and follow-up assessment (Xiao, 2003). PEIA is regarded as the application of EIA principle in strategy level. EIA emphasizes a better execution of specific actions, but PEIA focuses on the previous conditions in which the actions are inserted (Huo and Qiu, 2004).

Over ten years in the past, PEIA plays a key role in sustainable development process of China for it acts as a bridge between abstract, macroscopic sustainable strategy and concrete, feasible projects and promotes implementation of sustainable development principle. Many practices have been 
carried out in China, which concentrates on urban transport planning, industry structure adjustment, city planning, and energy planning etc. (Huang et al., 2003; Ma et al., 2003; Ju and $\mathrm{Zhu}, 2004)$.

PEIA has obtained great development in China both in theoretical research and practices, but there still have some limitation as following: (1) Undeveloped methodology of PEIA; (2) Insufficient assessment information and unpredictable uncertainty; (3) Inconvenience in scoping; (4) Difficulties in confirming the role of public participation and guaranteeing its validity; (5) The obstruction of the policy department; and (6) Limited cooperation and coordination between different departments.

This paper introduces the system construction of PEIA in China and discusses the approaches to improve it in the hope of providing theoretical support for PEIA practice in China and abroad. Section 1 reviews the background of SEA and PEIA in China and other countries. Section 2 summarizes the three developing phases and their characteristics of PEIA in China. In section 3, the current PEIA system in China, focusing on assessor, targets, requirements, contents, methods and working procedure of PEIA, etc. is introduced. Some suggestions for improving PEIA of China are given in section 4.

\section{The Developing Stages of PEIA in China and Their Characteristics}

Although PEIA in China is in a relatively early stage at present, it has made great progress both in theoretical research and practice in the last decades. The development of it can be divided into three stages as follows:

(1) Budding stage (1986 1992) - appeared in Regional Environmental Impact Assessment (REIA) form

REIA, with respect to its assessment level, targets and contents, belongs to SEA and it is regarded as the earliest form and important component of PEIA and even SEA in China (Xu et al., 2000; Meng et al., 2001; Li, 2002). In 1986, Environmental Quality Committee under China Environmental Sciences Society held an academic seminar in Shijiazhuang City, Hebei Province, the necessity of combining EIA of a single project with EIA of regional economic development area was emphasized. Subsequently, a series of academic conferences were convened, which promoted the research of REIA and established the foundation for the practice of REIA. In 1989, the first REIA project, REIA of midtown of Baiyin City, was carried out by Institute of Environmental Science of Beijing Normal University in China. Since then, many REIA cases, such as REIA of the new economic development zone of Meizhou Gulf in Fujian Province, REIA of Maanshan City, and so on, had been developed in succession, which predicted and analyzed the environmental impacts of regional development, and offered effective decision support for regional environmental management and plan (Peng, 1999).
(2) Formative stage $(1992 \sim 2003)$ - conducted in the plan level of SEA form

In 1992, Therivel et al. (1992) proposed the concept of SEA for the first time, and argued that SEA included three levels: policies, plans and programs. From then on, SEA of China is conducted in the plan level, namely PEIA. In theory field, most of research focused on: (1) the necessity, indexes system, working procedure and assessment methods of PEIA; (2) the relationship among PEIA, sustainable development strategy, project EIA, and comprehensive decision etc. ( $\mathrm{Li}$ and Yang, 1998; Bao and Shang, 1999). In the regulation construction, 21 Century Agenda of China (CSC, 1994) was issued, which states the need for objectives-led planning and broadening of the appraisal process to encompass the whole range of sustainability. And the State Council promulgated the Environmental Protection Management Ordinance for Construction Project (CSC, 1998), which regulates that EIA should be developed on regional development plans such as development in river basins, construction of development zones, construction new areas in cities, and transformation of old cities. In practice, REIA is still the major form of PEIA at this stage, and few other kinds of PEIA cases were conducted.

(3) Extension stage (2003 Onward) - implementing legally

On September $1^{\text {st }}, 2003$, China began to implement EIALPRC, which is a milestone of the PEIA work in China. It stipulates: "the relevant departments of the State Council, local people's governments at or above municipal level under which districts are established and their relevant departments shall organize and conduct environmental impact assessment on relevant plans of land use, plans of exploration, utilization and development in the areas, river basins and sea areas that are prepared by them in the process of planning, and shall provide writings or instructions concerning environmental impacts on these plans" and "the relevant departments of the State Council, local people's governments at or above municipal level under which districts are established, and their relevant departments shall organize and conduct environmental impact assessment on relevant specialized plans concerning industry, agriculture, pasturage, forestry, energy, water conservancy, communication, urban construction, tourism and exploration of natural resources (specialized plans) that are prepared by them before the drafts of such specialized plans are submitted for examination and approval, and shall submit environmental impact reports to the authority responsible for examining and approving such special plans." This shows that PEIA in China is in implementing legally period.

In less than two years, basis on EIALPRA and Technical guidelines for plan environmental impact assessment (on trial) (CNEPD, 2003), a lot of PEIA were carried out in practice, such as "PEIA for Haihe River bank of Tianjin City comprehensive development and transformation plan", "PEIA for Shanghai medium and long-term power construction plan", and "PEIA for Jinshan Island marine nature reserve protection plan", etc., which establish the foundation for further development of PEIA in China afterward. 


\section{Current PEIA System in China}

\subsection{The Assessor and Assessment Targets of PEIA}

According to EIALPRC, assessor of PEIA is selected by government or relevant departments who organizes and conducts the plan on the basis of actual condition. So, assessor of PEIA can be the government or relevant departments themselves, or assessment unit or expert panel trusted by government or relevant department, this is a principle of PEIA in China.

Some researchers argue that "internal assessment (selfassessment)" may lose the restraints on the governments and may led to low quality of PEIA, they propose that a third party should be selected to undertake PEIA. This suggestion did not be adopted by the drafter of EIALPRC, because the behavior of government constituting plans differs from that of construction projects evidently in attribute and level etc., and we cannot imitate project EIA fully, regulating all the PEIA should be completed by intermediary assessment institutions uniquely. Actually, in some developed countries, such as Canada, a self-assessment process of PEIA is promoted (CEAA, 1999). Furthermore, if the EIALPRC stipulates the assessor of PEIA must be the third part, things like revealing state secret may hinders governments from developing the plans.

Assessment targets of PEIA in China are the following plans, which are organized and conducted by relevant departments of the State Council, local people's governments at or above municipal level under which districts are established and their relevant departments:

(1) Relevant plans of land use, plans of exploration, utilization and development in the areas, river basins and sea areas. The directional plans among the relevant specialized plans concerning industry, agriculture, pasturage, forestry, energy, water conservancy, communication, urban construction, tourism and exploration of natural resources.

(2) The non-directional plans among the relevant specialized plans concerning industry, agriculture, pasturage, forestry, energy, water conservancy, communication, urban construction, tourism and exploration of natural resources (other plans except directional plans among the relevant specialized plans).

\subsection{The Assessment Requirements of PEIA}

As far as a plan of kind I is concerned, the PEIA should be conducted in the course of planning, and the writing or instruction concerning environmental impact on it should be provided. The PEIA writing or instruction should include statement of current environmental situation, analysis, forecast and assessment on possible environmental impact caused after the plan is implemented, and the countermeasures that prevent or mitigate the adverse environmental impact. The conclusion of PEIA is not necessary.

Concerning a plan of kind II, the PEIA should be devel- oped before the draft plan is submitted for examination and approval, and environmental impact report of the plan should be provided. The contents of the environmental impact report are as follows:

(a) Introduction;

(b) The profile of proposal plan;

(c) Statement of current situation of environment;

(d) Analysis and assessment on possible environmental impact;

(e) Recommended schemes and mitigation measures;

(f) Expert consultation and public participation;

(g) Monitoring and follow-up assessment, difficulty and uncertainty;

(h) Conclusion

Comparing with the writings or instructions concerning environmental impacts of the plans I, environmental impact reports of plans II should have exhaustive representations and explicit assessment conclusions.

\subsection{The Assessment Contents and Methods of PEIA}

According to "Technical guidelines for plan environmental impact assessment (on trial)", the assessment contents of PEIA include the following:

(a) Analysis of the plan: analyzing the relationship between objectives, indexes and schemes of the proposal plan and these of other relevant development plans or environmental protection plans.

(b) Investigation, analysis and assessment of current environmental situation: investigating, analyzing current state of the environment and historical evolvement, discerning the sensitive environmental problems and main factors restricting proposal plans.

(c) Identification of environmental impact and confirmation of environment goals and evaluation indexes: identifying major environmental problems and environmental impact of the objectives, indexes, schemes (including alternative schemes), confirming environmental goals according to relevant environmental protection polices, regulations and standards, selecting qualitative and quantitative evaluation indexes.

(d) Analysis, forecast and assessment of the environmental impact: predicting and assessing the impacts of various schemes (including alternative schemes) on environmental protection goal, environmental quality and sustainability.

(e) Presentation of feasible scheme harmonizing with environment for decision-making and mitigation measures: aiming at various schemes (including alternative schemes), identifying environmental protection measures, selecting first-selected scheme.

(f) Public participation. 
Table 1. Appraisal Methods Used in Each Assessment Section of PEIA

\begin{tabular}{|c|c|}
\hline Assessment section & Assessment method \\
\hline \multirow{4}{*}{$\begin{array}{l}\text { Screening plan schemes } \\
\text { primarily }\end{array}$} & Checklist \\
\hline & Matrix \\
\hline & Comparison, analogism and consistency analysis method \\
\hline & Expert consultation \\
\hline \multirow{2}{*}{$\begin{array}{c}\text { Investigating and analyzing the } \\
\text { background of environment }\end{array}$} & Collecting data, investigating and monitoring \\
\hline & GIS \\
\hline \multirow{6}{*}{$\begin{array}{l}\text { Discerning environmental } \\
\text { impact of plan }\end{array}$} & Checklist \\
\hline & Matrix \\
\hline & Network analysis \\
\hline & System flowing drawing \\
\hline & Analyzing hierarchy procedures \\
\hline & Scenario analysis \\
\hline \multirow[t]{4}{*}{ Public participation } & Discussion in meeting \\
\hline & Questionnaire \\
\hline & Public consultation \\
\hline & Mass media \\
\hline \multirow{9}{*}{$\begin{array}{l}\text { Forecasting and assessing } \\
\text { environmental impact of plan }\end{array}$} & Input-output analysis \\
\hline & Environmental mathematical model \\
\hline & Scenario analysis \\
\hline & Weighted comparison \\
\hline & Cost-benefit analysis \\
\hline & Analyzing hierarchy procedures \\
\hline & Sustainable development ability evaluation \\
\hline & Contrastive evaluation \\
\hline & Environment carrying capacity analysis \\
\hline \multirow{9}{*}{$\begin{array}{l}\text { Cumulative environmental } \\
\text { impact assessment }\end{array}$} & Expert consultation \\
\hline & Checklist \\
\hline & Matrix \\
\hline & Network analysis \\
\hline & System flowing drawing \\
\hline & Environmental mathematical model \\
\hline & Environmental carrying capacity analysis \\
\hline & Map overlays plus GIS \\
\hline & Scenario analysis \\
\hline
\end{tabular}

(g) Arranging monitoring and follow-up assessment plan.

(h) Compiling assessment file of PRIA (report, writing or instruction).

Presently, the assessment methods adopted in PEIA can be divided into two kinds: one is the methods used in project EIA and suitable for PEIA, such as those employed to discern environmental impact (checklist, matrix, network analysis), describing the state of the current environment, and forecast models for environmental impact etc.; the other is the methods utilized in the economic departments and planning research and adapted to PEIA, such as simulation analysis of various scenarios, regional prediction, input-output analysis, GIS, cost-benefit analysis, environment carrying capacity 


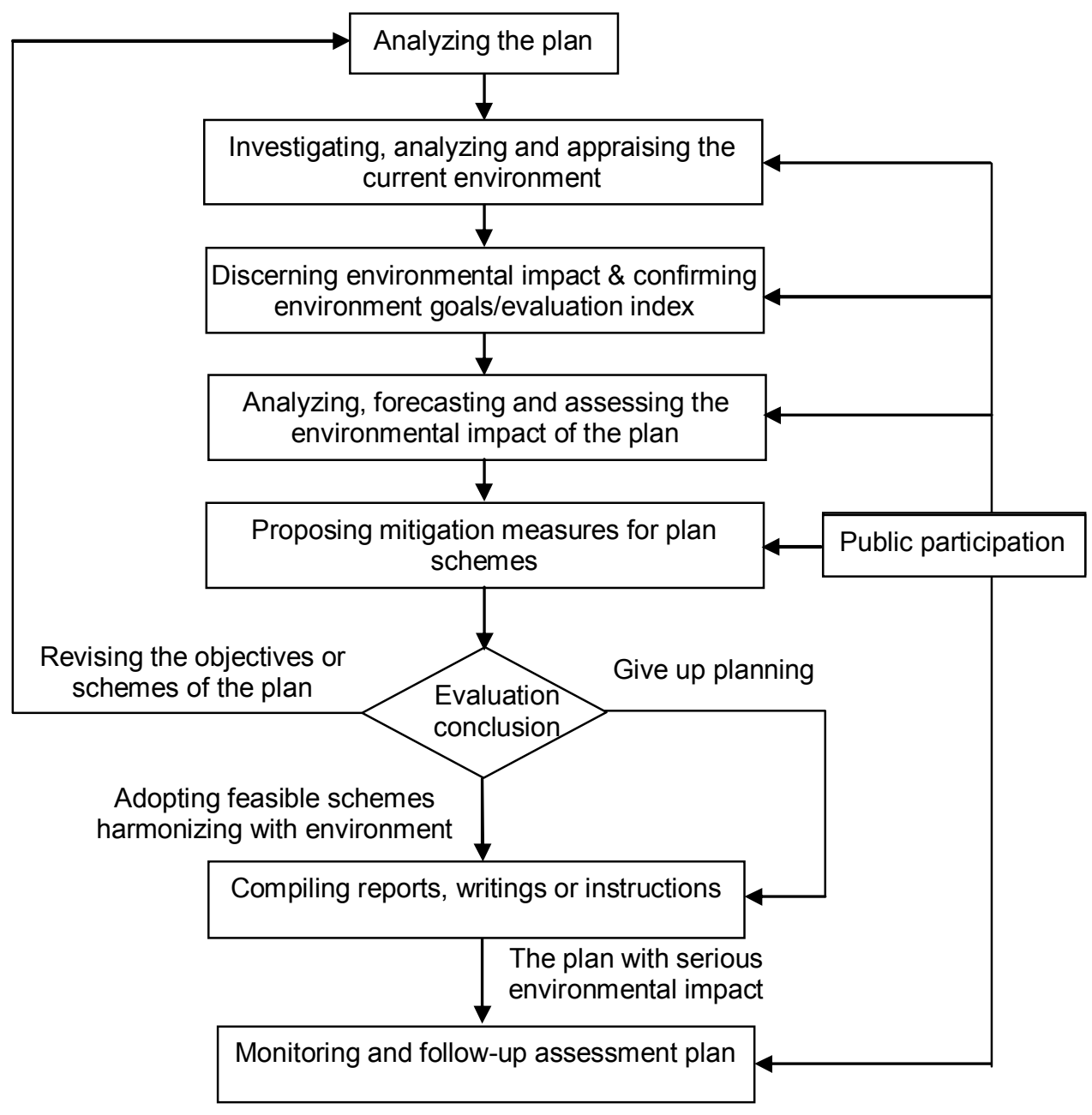

Figure 1. The working procedure of PEIA in China.

analysis, etc. Appraisal methods used in each assessment section is listed in Table1.

\subsection{The Working Procedure of PEIA}

According to "Technical guidelines for plan environmental impact assessment (on trial)", the working procedure of PEIA is as Figure 1 shows. The first step is plan analyzing; the second step is investigating, analyzing and appraising the current environment; the third step is discerning environmental impact and confirming environment goals and evaluation index; the fourth step is analyzing, forecasting and assessing the environmental impact; the fifth step is proposing mitigation measures for plan schemes. After these five steps, if the evaluation conclusion can be accept, then reports, writings or instruction need to be compiled, and monitoring and follow-up assessment plan need to be arranged. If after these five steps, the evaluation conclusion can not be accepted, ei- ther revising the objectives or schemes of the plan, doing these five steps again until its evaluation conclusion can be accepted, or giving up the plan. But the public participation is in all these steps, even in compiling reports, writings or instructions step and arranging monitoring and follow-up assessment step.

\section{Some Suggestions for Developing PEIA in China}

In the past decades, PEIA has undergone a perfecting process in China. During this period, a lot of valuable experiences have been accumulated and great economic and environmental benefit has been made. But PEIA is still in early stage in China, many aspects need to be improved. So, we give following suggestions:

(1) Following the principle of "intervening in early stage", achieving synchronous EIA of all plans 
According to EIALPRC, the assessment opportunity of plans I is "in the process of planning", and that of plans II is "before the drafts plans are submitted for examination and approval". It is obvious that the assessment opportunity of plans II is later than that of plans I, the reason of which is that most of plans II are departmental, professional, and halfdetermined, the scales of plans II are relatively small, the environmental impacts of them are relatively light, and the possibility of controlling and adjusting them is relatively great. So EIA for plans II is carried out after the drafts is formed.

However, the PEIA, for all kinds of plans, should intervene in the process of planning as early as possible, because the earlier the PEIA is conducted, the greater the efficiency of the PEIA is, i.e., the principle of "intervening in early stage" (Steve and Keith, 2000). We propose that when the opportunity is appropriate, the synchronous appraisal of plans II should be legally required.

(2) Implementing classification management on PEIA according to the degree of environmental impacts of plans

According to EIALPRC, the PEIA should be conducted on all plans I, II and the writings or instructions concerning environmental impacts, environmental impact reports of all plans should be submitted to the authority responsible for examining and evaluating them.

For PEIA, the step of initial screening needs to be put into the working procedure in order to identify the necessity of PEIA. After this step, all plans can be divided into three kinds: (1) plans which PEIA is needed; (2) plans which PEIA is not needed; and (3) plans whether PEIA is needed or not is not very clear (Rosa and Natalia, 2000; Shang and Bao, 2003).
As to the $3^{\text {rd }}$ kind of plans, initial environmental evaluation (IEE) should be carried out in order to identify the necessity of PEIA further. If the environment impact of a plan is evaluated to be serious after IEE, it returns to be the $1^{\text {st }}$ kind, otherwise, it returns to be the $2^{\text {nd }}$ kind.

Furthermore, we can implement classification management on PEIA, which can consult those in the project EIA in China. An environmental impact report shall be written in case that serious environmental impact may be caused so as to conduct a comprehensive assessment on the environmental impact generated by the plan, and an environmental impact statement shall be compiled in case that light environmental impact may be caused so as to conduct an analysis or assessment of the plan on the environmental impact.

Here, we suggest: (a) take the step of IEE, the PEIA is conducted only on plans with adverse environmental impacts after implementation, otherwise just an environmental impact registration form is needed to filled in; and (b) for plans needing PEIA, whether an environmental impact report or an environmental impact statement is needed may be determined by the environmental impact degree of the plan.

(3) Realizing efficiency of alternative schemes in the process of planning

Alternative schemes are other possible fact ones which can realize common strategic objective with proposed scheme (Shang, 2003). The optimization and selection of alternative schemes is a key for PEIA. As to plans I, alternative schemes are proposed by the drafters after objectives of plans are determined. At this time, assessor screens all alternative schemes primarily. The alternative schemes after screening

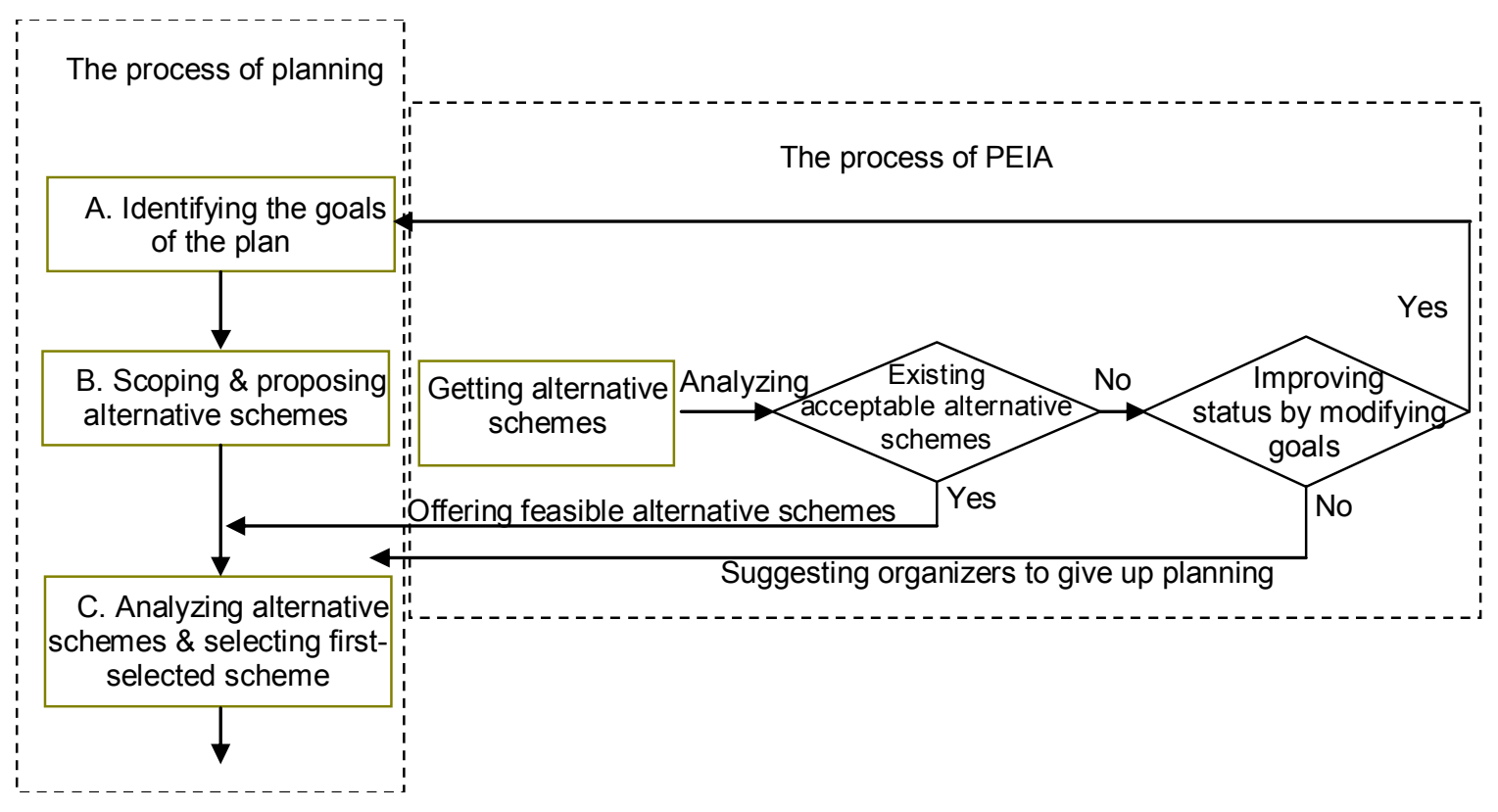

Figure 2. Function of alternative schemes in the process of planning. 
may be some of the alternative schemes themselves or revision schemes of them. After this, the drafters choose the first-selected scheme from the alternative schemes supplied by assessor. Here, such circumstance may exist that none of environmental impacts of alternative schemes (revision schemes of alternative schemes) is acceptable. At this moment, assessor should advise the drafters revise the objectives so that the alternative schemes can meet the demands of environmental protection. But if the environmental impacts of alternative schemes are still unable to reduce to be acceptable, assessor should suggest organizers to adopt do-noting alternative, namely giving up planning (as Figure 2 shows).

\section{Conclusions}

During the latest ten years, PEIA has gone through a developing course in China, and a series of PEIA system has been constructed, which has performed an important function in controlling environmental pollution and safeguarding Chinese people's health. But there still have some respects to be improved, such as: methodology of PEIA, approach of collecting assessment information and reducing unpredictable uncertainty; scoping method; public participation; cooperation and coordination between different departments, etc. And we can developed PEIA by following measures: conforming to the principle of "intervening in early stage", carrying out PEIA for all plans in the process of planning; implementing classification management on PEIA according to the degree of environmental impacts of plans; and analyzing acceptability of alternative schemes step by step to enhance efficiency of PEIA. Without doubt, under the guidance of EIALPRC, the system of PEIA in China will be improved constantly, and will play a more important role in coordination with the development of economy, society and environment in the future.

\section{References}

Arce, R. and Gullón, N. (2000). The application of Strategic Environmental Assessment to sustainability assessment of infrastructure development. Environ. Impact Assess. Rev., (20), 393-402.

Bao, C.H. and Shang, J.C. (1999). The theories and methods system of Strategic Environmental Assessment in China. Environ. Herald, (5), 1-4.

Bao, C.K., Lu, Y.S. and Shang, J.C. (2004). Framework and operational procedure for implementing Strategic Environmental Assessment in China. Environ. Impact Assess. Rev., 24(1), $27-46$.

Bonnell, S. and Storey, K. (2000). Address cumulative effects through Strategic Environmental Assessment: A case study of small hydro development in Newfoundland, Canada. J. Environ. Assess. Policy Manage., 2(4), 477-499.

Carson, J.E. (1992). On the preparation of environmental impact states in the Unites States of American. Atmos. Environ., 26(15), $2759-2768$

CEAA (Canadian Environmental Assessment Agency) (1999). Cabinet Directive on the Environmental Assessment of Policy, Plan and Program Proposals: Guidelines for Implementing the Cabinet Directive, Minister of Supply and Services of Canadian.

CSC (China State Council) (1994). $21^{\text {st }}$ Century Agenda of China:
White Book of China's Population, Environment and Development, China Environmental Science Press.

CSC (China State Council) (1998). Environmental Protection Management Ordinance for Construction Project.

CNPCSC (China National People's Congress Standing Committee) (2002). Environmental Impact Assessment Law of the People's Republic of China.

CNEPD (China National Environmental Protection Department) (2003). Technical Guidelines for Plan Environmental Impact Assessment (on trial).

Dodgn, J. (1997). Issues in evaluation the long-term global impacts of transport policy. Environ. Pollut., 7(3), 293-304.

EIALPRC (Environmental Impact Assessment Law of the P.R. China) (2002). Adopted by China National People's Congress Standing Committee on October $28^{\text {th }}$.

Environmental Protection Management Ordinance for Construction Project (1998). Approved by China State Council on November $18^{\mathrm{tn}}$.

Gardiner, J.L. (1994). Sustainable development for river catchment. $J$. Inst. Water Environ. Manage., (8), 308-319.

Huang, X.S. and Tang, S.J. (2003). Legal ponder over the agent of environmental impact assessment. J. Chongqing Jianzhu Univ., 25 (6), 105-107.

Huang, Y.Y., Ma, W.C. and Yu, Q. (2003). Mathematical modeling for air quality prediction in environmental assessment of urban comprehensive transportation planning. Shanghai Environ. Sci., $22(5), 335-345$.

Huo, S.Q. and Qiu, H. (2004). Comparing between planning environmental impact assessment and project environmental impact assessment. Security, hyg. environ. prot. railway work, 31 (3), 151-153.

$\mathrm{Ju}, \mathrm{M}$. and Zhu, T. (2003). Thinking on the important issues of planning environmental impact assessment in China. Shanghai Environ. Sci., (Suppl.), 80-83.

Ju, M. and Zhu, T. (2004). The initial study of Strategic Environmental Assessment of city planning. China Dev., (1), 37-41.

Kahen, G. (1997). Energy technology transfer: A proposal for the strategic assessment of environmental impact within developing countries. Energy Environ., 8(2), 115-131.

Li, S.S. (2002). Strategic Environmental Assessment and regional environmental impact assessment. China Environ. Sci., 20 (Suppl.), 59-63.

Li, W. and Yang, Z.F. (1998). Strategic environmental impact assessment toward sustainable development. China Environ. Sci., 18 (Suppl.), 66-69.

Ma, X.M., Zhang, L.X. and Dai, D.J. (2003). Method and example of Strategic Environmental Assessment for industry structure adjustment. Acta Sci. Nat. Univ. Pekinensis, 39(4), 565-571.

Meng, X.L., Wu, B. and Su, D.L. (2001). Approach on the practice and development of Strategic Environmental Assessment. Environ. Assess., 27(105), 36-46.

Noble, B.F. (2000). Strategic Environmental Assessment: what is it and what makes it strategic? J. Environ. Assess. Policy Manage., 2(2), 203-224.

Noble, B.F. (2003). Integrating Strategic Environmental Assessment with industry planning: A case study of the Pasquai-Porcupine Forest Management Plan, Saskatchewan, Canada. Environ. Manage., (1), 401-411.

Peng, Y.D. (1999). Regional Development Environmental Impact Assessment, China Environmental Science Press.

Shang, J.C. and Bao, C.H. (2003). Introduction of Strategic Environmental Assessment, Science Press, Beijing.

Therivel, R., Wilson, E., Thompson, S., et al. (1992). Strategic Environmental Assessment, Earthscan Publication Ltd.

Therivel, R. and Paridario, R.M. (1996). The Practice of Strategic 
Environmental Assessment, Earthscan Publication Ltd.

Xiao, H.S. (2003). Index system and method of environmental impact assessment in planning. Metal Mine, (12), 46-49.
Xu, H., Zhu, T. and Jia, C.R. (2000). Development of Strategic Environmental Assessment in China-regional environmental assessment. Urban Environ. Ecol., 13(3), 4-10. 